\title{
Designing a comprehensive separated regulation mechanism of distribution companies considering short- and long-term asset management
}

\author{
Sayed Majid Miri Larimi ${ }^{1} \bowtie$, Mahmoud-Reza Haghifam ${ }^{1}$, \\ Mansoreh Zangiabadi ${ }^{2}$, Mohammad Hassan Bahmani ${ }^{1}$ \\ ${ }^{1}$ Tarbiat Modares University, Tehran, Iran \\ ${ }^{2}$ Newcastle University, Newcastle, UK \\ 凶E-mail:m.miri@modares.ac.ir
}

\begin{abstract}
The regulation of distribution system operator is changing from the traditional approach to performance-based regulation (PBR). In this study a novel PBR approach is proposed for the regulation of a distribution company with consideration for asset management time scopes. In this regard a comprehensive separated regulation mechanism is presented so that the total expenditure for asset management is categorised into two: capital expenditure (Capex) and operational expenditure (Opex). A separate Capex and Opex regulation is proposed for electric distribution company regulation. A new reward and penalty scheme is proposed to efficiently regulate the quality of the network at a desirable level. The proposed methods are applied on the Iranian electricity distribution company.
\end{abstract}

\section{Introduction}

Historically, distribution system operators (DSOs) have been regulated by two regulation methods namely 'cost of service' and 'rate of return'. Under these methods the profit of DSOs was somehow dependent on their costs; they had very little incentive to improve their efficiency [1-3]. To provide an incentive for DSOs, performance-based regulations (PBR) are introduced to motivate the DSOs to improve their efficiency and decrease costs [4]. PBR is a tool in the regulatory scheme for providing incentives to a regulated operator to behave in such a way that public interest is promoted.

Although the proposed regulations motivate the DSOs to increase their efficiency and cut costs, they lack incentives for service quality and reliability [5]. Owing to the inherent weaknesses of the PBR, regulators employ various forms of RPS to ensure reliability. RPS induces the DSOs to provide reliable services through penalising poor performance and rewarding good performance [6].

A typical form of the penalty/reward scheme is shown in Fig. 1. As shown, the general form of RPS contains three zones: reward, dead and penalty zones. The dead area is where neither a penalty nor a reward is assessed. The penalty and reward areas are where the performance of DSO is in poor and good levels, respectively.

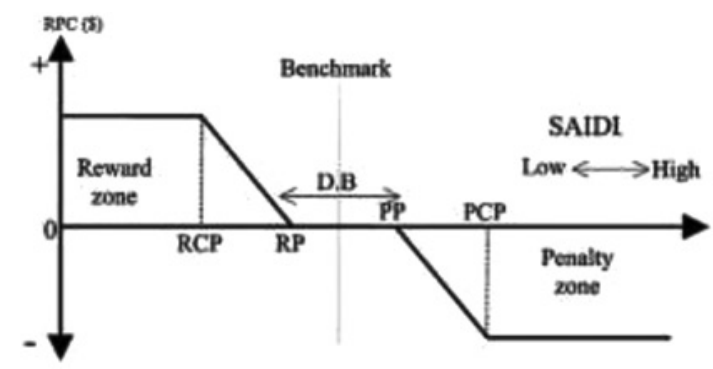

Fig. 1 A general RPS
The reason for using a dead zone is to dampen unintended penalties and rewards owing to stochastic variations in quality. The penalty and reward areas are where the performance of a DSO is in good and poor levels, respectively. As the reliability of service is worsened or improved the penalties or rewards increase respectively, and are capped where a certain value is reached $[6,7]$. The reliability indices utilised in RPS work is based on system average measures of interruption, such as system average interruption duration index (SAIDI) and system average interruption frequency index (SAIFI) [8]. SAIDI is used in this paper as the reliability index.

Utilising a reliability index in RPS is proposed in [9-12]. In [13] an algorithm to obtain the parameters of RPS for each electric company by using data envelopment analysis (DEA) and fuzzy $c$-means (FCM) clustering is presented. A new method for designing RPS-based Yardstick theory is proposed in [14].

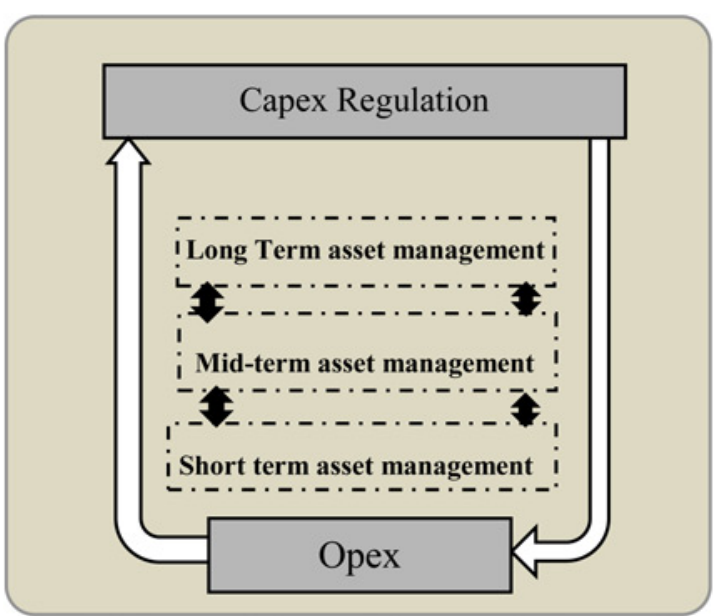

Fig. 2 Separated regulation mechanism 
Defining the scope of work

- Objective: comprehensive regulation scheme

- Regulatory period definition

- DisCos clustering

- Regulatory parameter definition: Opex, Capex, quality

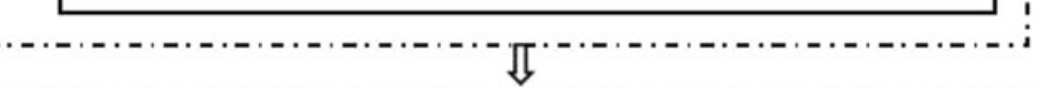

Similar Company Clustering

- Select a set of variable to cluster similar companies

- fuzzy c-means clustering (FCM)

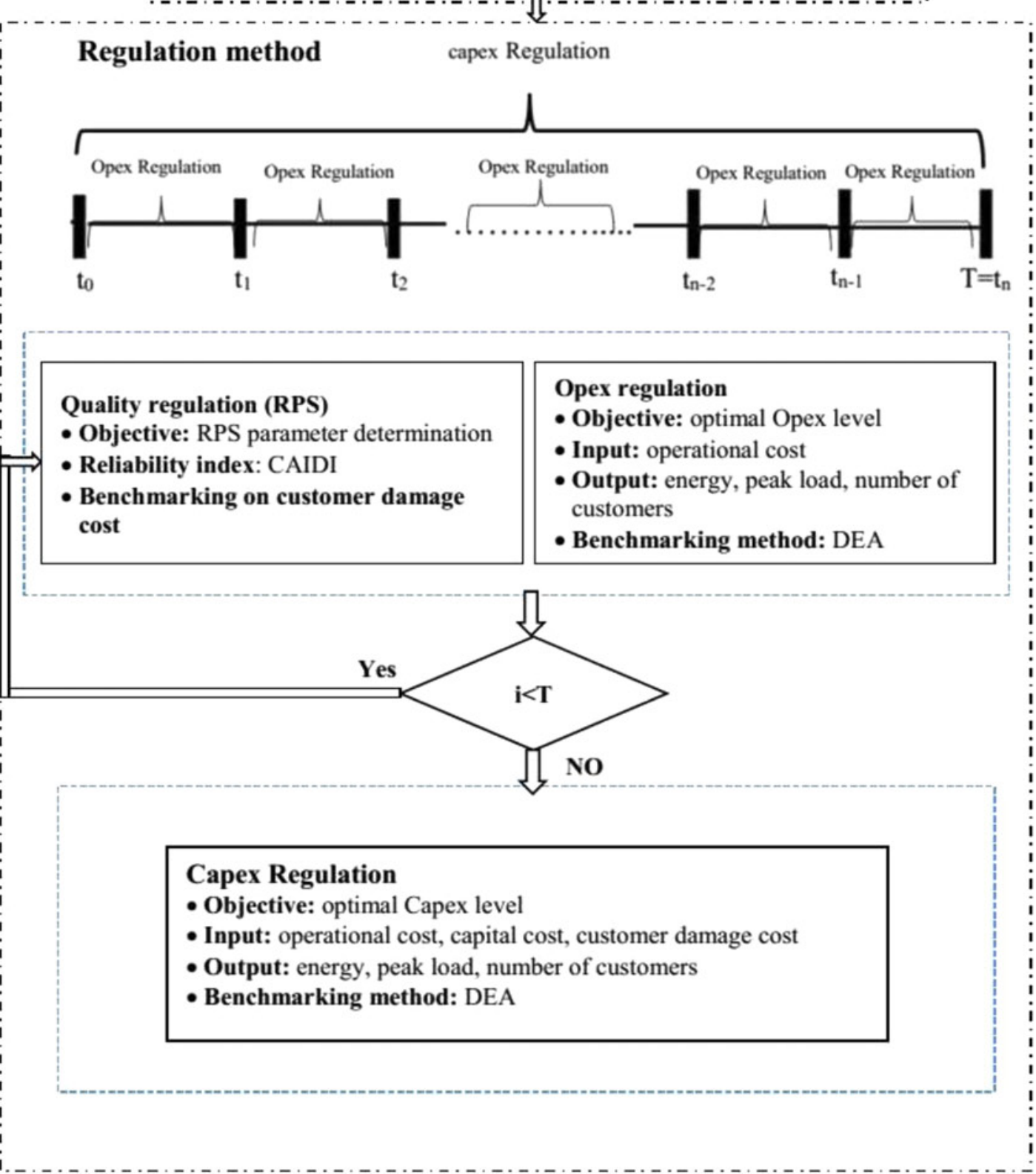

Fig. 3 General framework of the proposed regulation method 
On the other hand, the global trend today is a movement towards a more efficient electric distribution system and optimal utilisation of available resources, in which asset management plays a decisive role [15]. Asset management should contain strategic planning, maintenance, utilisation, and operation of a physical resource. The major challenge for a distribution company is to optimally manage its assets along with its objectives, considering that there is a battle between improving service reliability and controlling costs. Possible time scales of asset management are real time, short term, midterm and long term [16]. From a practical standpoint, there are inter-relationships between the aforementioned timescales, additionally it is known that the coordination of an asset management's timescales plays a critical role in strategic decision making because of the actions occurring within each timescale interacts [17].

In all the regulation strategy, this coordination has not been considered. With regard to this issue, in this paper, as shown in Fig. 2, a comprehensive separated regulation mechanism is presented so that the total expenditure for asset management is categorised to capital expenditure (Capex) and operational expenditure (Opex). The separate Capex and Opex regulation is proposed for efficient electric distribution company regulation.

\section{Proposed method}

This paper considers short- and long-term asset management and a comprehensive separated regulation mechanism of a distribution company. The general framework of the proposed method is shown in Fig. 3. The main objective of this paper is to determine the optimal level of Opex and Capex as well as RPS parameters. In this regard, at first similar companies are clustered by fuzzy clustering method (FCM) based on factors that are outside the control of the companies into different groups. [13] The variables used for carrying out such classification are based on weather conditions and network conditions. These variables are maximum temperature $\left({ }^{\circ} \mathrm{C}\right)$, minimum temperature $\left({ }^{\circ} \mathrm{C}\right)$, precipitation $(\mathrm{mm})$, average wind speed (knot) and number of days with thunder, density [number of customers per service area $\left(\mathrm{C} / \mathrm{km}^{2}\right)$ ] and quantity of energy supplied (MWh).

Then the optimal level of Opex of the $i$ th year is determined by the following equation:

$$
\operatorname{Opex}_{\mathrm{opt}, k}^{i}=\operatorname{Opex}_{k}^{i} \theta_{o, k}^{i}
$$

where $\operatorname{Opex}_{\mathrm{opt}, k}^{i}$, Opex ${ }_{k}^{i}$ and $\theta_{o, k}^{i}$ are the optimal level of Opex, operational cost and efficiency score of $k$ th DisCo, respectively. The efficiency score is computed by DEA by considering operational cost as the input and the energy, number of customers and peak load as the output of DEA [13]. Once the optimal Opex is determined the RPS parameter is calculated as the following.
Centre of dead zone (CDZ): this parameter is determined by the following equation:

$$
\mathrm{CDZ}_{K}=\operatorname{Ave}_{K}\left(1+\frac{\mathrm{RI}_{\text {max }}\left(\theta_{\text {max }, j}^{\mathrm{cdf}}-\theta_{k}^{\mathrm{cdf}}\right)}{\left(\theta_{\text {max }, j}^{\mathrm{cdf}}-\theta_{\text {min }, j}^{\mathrm{cdf}}\right)}\right)
$$

where $j$ denotes the cluster of the company, $\mathrm{Ave}_{k}$ is the historical average reliability index of company $k, \mathrm{RI}_{\max }$ maximum reliability index improvement and $\theta^{\text {cdf }}$ is the efficiency score which is calculated considering customer damage cost as the input of the DEA method.

Dead zone width: In this paper, it is determined to equal the average standard deviation (SD) of the historical reliability index for each cluster [18].

Max penalty and reward: these parameters are determined as proposed in [13].

Reward and penalty ramp: The main objective of this paper is to improve the quality of companies with low-quality levels and prevent the deterioration of the level of quality. In this paper, the reward and penalty ramp is determined by the following equation:

$$
\mathrm{RS}=\frac{\partial \mathrm{CIC}}{\partial \mathrm{RI}}
$$

where CIC is customer interruption cost and RI is the reliability index. The annual CIC can be estimated with the method proposed in [19].

The optimal level of Capex is determined at the end of the regulatory period by the following equation:

$$
\operatorname{Capex}_{\mathrm{opt}, k}=\operatorname{Opex}_{k} \theta_{c, k}
$$

where Capex $\mathrm{opt}, k$, Opex $_{k}$ and $\theta_{c, k}$ are the optimal level of Capex, capital expenditure and efficiency score of $k$ th DisCo, respectively. The efficiency score is computed by DEA by considering operational interruption cost, capital interruption cost and CIC at the regulatory period as the input and the energy, with the number of customers and peak load as the output of DEA [13].

\section{Case study}

The proposed method is tested on the Iranian distribution companies. There are 39 electricity distribution companies in Iran and the information on these companies is available at: www.tavanir.org. Other required information is taken from [13]. Due to the page constraint the regulatory period considered is 4 years and the results are determined for the first cluster of the result of [13]. The results of this paper are given in Table 1.

\begin{tabular}{|c|c|c|c|c|c|c|c|}
\hline \multirow[t]{2}{*}{ Company } & \multirow[t]{2}{*}{ Optimal Opex, M\$ } & \multicolumn{5}{|c|}{ Reward and penalty scheme } & \multirow[t]{2}{*}{ Optimal Capex, M\$ } \\
\hline & & $\mathrm{CDZ}, \mathrm{mm}$ & $\mathrm{SD}, \min$ & $\mathrm{RS}, \mathrm{M} \$ / \mathrm{nnn}$ & $\operatorname{Max} P, \mathrm{M} \$$ & $\operatorname{Max} R, \mathrm{M} \$$ & \\
\hline$A_{1}$ & 11.24 & 342 & 158 & 0.012 & -1.818 & 1.371 & 13.92 \\
\hline$A_{2}$ & 16.32 & 364 & 158 & 0.028 & -5.926 & 2.870 & 22.45 \\
\hline$A_{3}$ & 10.54 & 215 & 158 & 0.0101 & -0.853 & 0.141 & 17.14 \\
\hline$A_{4}$ & 15.63 & 589 & 158 & 0.014 & -1.504 & 1.504 & 21.16 \\
\hline$A_{5}$ & 42.80 & 2724 & 158 & 0.032 & -2.275 & 2.275 & 28.18 \\
\hline$A_{6}$ & 16.45 & 653 & 158 & 0.028 & -3.882 & 1.969 & 17.16 \\
\hline$A_{8}$ & 15.87 & 436 & 158 & 0.022 & -2.854 & 0.270 & 20.24 \\
\hline$A_{9}$ & 28.42 & 1734 & 158 & 0.036 & -3.877 & 3.877 & 34.32 \\
\hline$A_{10}$ & 12.22 & 501 & 158 & 0.042 & -2.793 & 2.793 & 10.8 \\
\hline$A_{11}$ & 11.23 & 396 & 158 & 0.013 & -4.535 & 3.267 & 14.64 \\
\hline$A_{12}$ & 9.62 & 842 & 158 & 0.013 & -7.773 & 5.346 & 22.43 \\
\hline$A_{13}$ & 15.26 & 1045 & 158 & 0.011 & -2.613 & 2.613 & 12.42 \\
\hline
\end{tabular}

In this table, parameters of RPS and optimal level of Opex and Capex are given. The average SD for the considered cluster is

Table 1 Result of the proposed method 
$158 \mathrm{~min}$ and the width of the dead zone is equal to this value. Using the formula of (2) and (3) the CDZ and ramp of reward and penalty scheme is determined for each company respectively. Other parameters of RPS are determined based on [13]. The optimal level of Opex and Capex is calculated based on each distribution company efficiency score and the real cost.

\section{Conclusion}

To provide an incentive, PBR is introduced to motivate the DSOs to improve the quality and efficiency by increasing the reliability index and decreasing the operational and capital costs respectively. Distribution companies use different asset management strategies to achieve this objective. Due to the inter-relations between timescales of asset management, the integration of timescale impact on regulation strategy plays a critical role. With regard to this issue in this paper, the total cost of each company was categorised into the operational interruption cost, capital interruption cost and CIC. Then the DEA was implemented on the distribution companies in three steps based on the efficiency score which was calculated with each step having the optimal level of Opex and Capex as well as efficient parameter of the reward and penalty scheme determined. The proposed algorithm creates financial incentives for distribution companies to improve or maintain their quality levels on the one hand, and control their operational and capital costs on the other. Also the long-term investment will be optimally done as it is required.

\section{References}

1 Navarro, P: 'Simple analytics of performance-based ratemaking: a guide for the PBR regulator, the', Yale J. Regul., 1996, 13, p. 105

2 Wang, J., Ngan, H., Engriwan, W., et al.: 'Performance based regulation of the electricity supply industry in Hong Kong: an empirical efficiency analysis approach', Energy Policy, 2007, 35, (1), pp. 609-615

3 Giannakis, D., Jamasb, T., Pollitt, M.: 'Benchmarking and incentive regulation of quality of service: an application to the UK electricity distribution networks', Energy Policy, 2005, 33, (17), pp. 2256-2271
4 Jamasb, T., Pollitt, M.: 'International benchmarking and regulation: an application to European electricity distribution utilities', Energy Policy, 2003, 31, (15), pp. $1609-1622$

5 Spence, A. M.: 'Monopoly, quality, and regulation', Bell J. Econ., 1975, pp. $417-429$

6 Mohammadnezhad-Shourkaei, H., Abiri-Jahromi, A., Fotuhi-Firuzabad, M. 'Incorporating service quality regulation in distribution system maintenance strategy', IEEE Trans. Power Deliv., 2011, 26, (4), pp. 2495-2504

7 Simab, M., Alvehag, K., Söder, L., et al.: 'Designing reward and penalty scheme in performance-based regulation for electric distribution companies', IET Gener. Transm. Distrib., 2012, 6, (9), pp. 893-901

8 Brown, R. E., Burke, J. J.: 'Managing the risk of performance based rates', IEEE Trans. Power Syst., 2000, 15, (2), pp. 893-898

9 Billinton, R., Pan, Z.: 'Historic performance-based distribution system risk assessment', IEEE Trans. Power Deliv., 2004, 19, (4), pp. 1759-1765

10 Fumagalli, E., Schiavo, L., Delestre, F.: 'Service quality regulation in electricity distribution and retail' (Springer Science \& Business Media, Berlin, 2007)

11 Billinton, R., Pan, Z.: 'Incorporating reliability index probability distributions in financial risk assessment with performance based regulation', Electr. Power Compon. Syst., 2005, 33, (6), pp. 685-697

$12 \mathrm{Xu}, \mathrm{N} .$, Wen, F., Huang, M., et al.: 'Optimal parameter setting of performance based regulation with reward and penalty'. 2007 IEEE Congress Evolutionary Computation, Singapore, Singapore, IEEE, 2007, pp. 2740-2744

13 Simab, M., Alvehag, K., Soder, L., et al.: 'Designing reward and penalty scheme in performance based regulation for electric distribution companies', IET. Gener. Transm. Distrib., 2012, 6, (9), pp. 893-901

14 Jooshaki, M., Abbaspour, A., Fotuhi-Firuzabad, M., et al.: 'A new reward-penalty mechanism for distribution companies based on concept of competition'. IEEE PES Innovative Smart Grid Technologies, Europe, Istanbul, Turkey, IEEE, 2014, pp. $1-5$

15 Catrinu, M. D., Nordgård, D. E.: 'Integrating risk analysis and multi-criteria decision support under uncertainty in electricity distribution system asse management', Reliab. Eng. Syst. Saf., 2011, 96, (6), pp. 663-670

16 Shahidehpour, M., Ferrero, R.: 'Time management for assets: chronological strategies for power system asset management', IEEE Power Energy Mag., 2005, 3, (3), pp. 32-38

17 Tor, O., Shahidehpour, M.: 'Power distribution asset management'. 2006 IEEE Power Engineering Society General Meeting, Montreal, Quebec, Canada, IEEE, 2006, p. 7

18 Mohammadnezhad-Shourkaei, H., Fotuhi-Firuzabad, M., Billinton, R. 'Integration of clustering analysis and reward/penalty mechanisms for regulating service reliability in distribution systems', IET. Gener. Transm. Distrib., 2011, 5, (11), pp. 1192-1200

19 Alvehag, K: 'Risk-based methods for reliability investments in electric power distribution systems', Alvehag, Karin, KTH, School of Electrical Engineering (EES), Electric Power Systems, 2011 